\title{
A Prebiotic Surface Catalysed Photochemically Activated Synthesis of L-Cysteine
}

\author{
Nigel AYLWARD \\ School of Chemistry and Molecular Biosciences \\ University of Queensland, \\ Brisbane, Queensland, Australia \\ e-mail: uqnaylwa@uq.edu.au
}

\begin{abstract}
Ethyne forms a weak charge-transfer complex with surface catalysts such as Mg.porphin in which the ethyne group has a net positive charge $(0.08)$, and the conjugated porphin has a negative charge. This neutral complex is polarised and undergoes a nucleophilic addition reaction with ammonia at the carbene carbon to form Mg.2-amino ethenyl.porphin which has a tendency to the formation of cyclic Mg.1H aziridin-2yl.porphin complex. Nucleophilic attack by hydrosulfide anion ultimately yields a complex of bound 2-mercapto ethanimine. When the imine is bound to a Mg.porphin complex in which carbon monoxide has been oriented by exciting radiation an aziridine-2one complex is formed hydrolysable to the amino acid L-cysteine. The reactions have been shown to be feasible from the overall enthalpy changes in the ZKE approximation at the HF and MP2 /6-31G* level.
\end{abstract}

Keywords-ethyne; 2-amino ethenyl.porphin; 2-mercapto ethanimin-1yl porphin; l-cysteine

\section{INTRODUCTION}

L-cysteine, $\alpha$-amino- $\beta$-thiolpropionic acid [1], Cys,C [2] is a non-essential amino acid with $\mathrm{pKa}_{\mathrm{COOH}} 1.71, \mathrm{pKa}_{\mathrm{NH}}$ 10.78 , and $\mathrm{pKa}_{\mathrm{SH}} 8.33$ [2]. It is present in practically all proteins such as wool keratin, insulin, ovalbumin, myosin, [1], cytochromes [3], immunoglobulins and the posterior pituitary hormones, oxytocin and vasopressin [3]. Higher plants and many microorganisms utilize sulfate assimilation [3] reducing it from sulfate to sulfide where it is incorporated to form L-cysteine [3]. In mammals cysteine is formed from L-methionine [2]. The chemical synthesis and chirality have been determined [1]. L-Cystine has -S-S- disulfide bonds which may form intrachain or interchain cross-linking bridges in polypeptides [4].

From a prebiotic perspective [5] it is desirable if the reactant molecules formed spontaneously from a supposed prebiotic atmosphere to be inevitably present. It has often been held that the atmosphere of the Earth was originally mildly reducing $[2,6]$ implying the presence of concentrations of carbon monoxide, ammonia, water, hydrogen and hydrogen sulfide. It is also supposed that alkynes such as acetylene [7-8] were present as found on Titan, a moon of Saturn [9]. It has also been demonstrated that porphin may act as a catalyst for the formation of sugars [10] and polyenes [11].

This paper proposes a model for the catalytic photochemically activated formation of L-cysteine from the gases, acetylene, ammonia, carbon monoxide, hydrogen, hydrogen sulfide, water and the catalyst magnesium porphin..

The reactions described have been deduced as kinetically and thermodynamically viable, but photochemical excitation is required.

\section{PROBLEM FORMULATION}

The computations tabulated in this paper used the GAUSSIAN98 [12] commercial package. The standard calculations at the HF and MP2 levels including zero-point energy corrections [13], together with scaling [14], using the same basis set, 6-31G*, are as previously published [5]. Enthalpy changes at the HF level not including scaled zero point energies are designated as $\Delta \mathrm{H}$. The charge transfer complexes are less stable when calculated at the Hartree Fock level [13].

If the combined energy of the products is less than the combined energy of the reactants it may show that the reaction is also likely to be spontaneous at higher temperatures. This paper uses the atomic unit of energy, the hartree [12]. $1 \mathrm{~h}=627.5095 \mathrm{kcal} \cdot \mathrm{mol}^{-1} .1 \mathrm{~h}=4.3597482 \mathrm{x}$ $10^{-18} \mathrm{~J}$

\section{PROBLEM SOLUTION}

\section{A. Total Energies (Hartrees)}

Mg.porphin is a powerful catalyst able to form charge transfer complexes with a number of different kinds of molecules [15, 16-17]. With acetylene the ligand is positively charged (0.08) and the porphin has a negative charge. The acetylene sets as ligand with a linear $\mathrm{H}-\mathrm{C} \equiv \mathrm{C}-\mathrm{H}$ structure as shown.

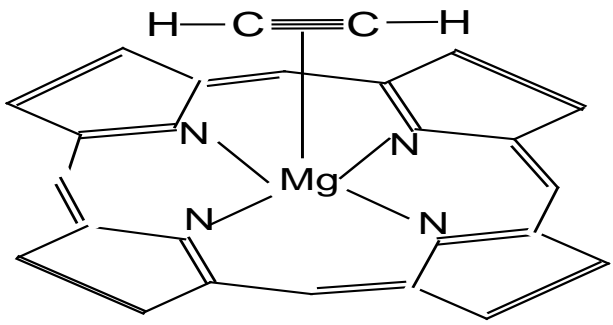

Figure 1. Mg.1, ethynyl.porphin $\Delta \mathrm{H}=-0.01807 \mathrm{~h}$ 


$$
\text { Mg.porphin }+\mathrm{H}-\mathrm{C} \equiv \mathrm{C}-\mathrm{H} \rightarrow
$$

The total energies and zero point energies for the HF and (1) MP2/6-31G* equilibrium geometries of molecules involved in the synthesis are given in Table I.

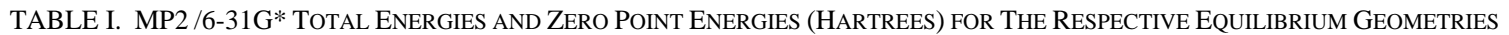

\begin{tabular}{|c|c|c|}
\hline Molecule & MP2 hartrees & ZPE (HF) hartree \\
\hline Mg.porphin & -1185.12250 & 0.29262 \\
\hline Mg.1, ethynyl.porphin & -1262.20848 & 0.32333 \\
\hline L-cysteine & -720.39287 & 0.11714 \\
\hline cis Mg.1, 2-amino ethenyl.porphin & -1318.54885 & 0.36958 \\
\hline trans Mg.1, 2-amino ethenyl.porphin & -1318.53002 & 0.36860 \\
\hline Mg.1, 2-amino ethylidene.porphin. & -1318.50125 & 0.36526 \\
\hline Mg.1,1H-aziridin-2-yl.porphin & -1318.55322 & 0.37028 \\
\hline Mg.1,1-amino-2-mercapto ethan-1yl.porphin ${ }^{-}$ & -1716.84855 & 0.37193 \\
\hline Mg.1, 2-mercapto ethanimin-1yl.porphin & -1716.27125 & 0.36262 \\
\hline 2-mercapto ethanimine & -531.11401 & 0.07440 \\
\hline Mg.porphin.CO & -1297.93784 & 0.30434 \\
\hline Mg.1, 2-mercapto ethanimin-1yl.porphin.CO & -1829.26645 & 0.37328 \\
\hline Mg.1,3-(mercaptomethanyl) aziridine-2-one-1-yl.porphin & -1829.27372 & 0.37324 \\
\hline Mg.1, S-methyl 2-thia ethanimin-1-yl.porphin & -1755.44790 & 0.39465 \\
\hline Mg.1, S-methylthia-2-aza-cyclobutan-3-yl.porphin & -1755.30445 & 0.39346 \\
\hline $\mathrm{NH}_{3}$ & -56.35421 & 0.03700 \\
\hline $\mathrm{SH}^{-}$ & -398.21045 & 0.00628 \\
\hline $\mathrm{CO}$ & -113.02122 & 0.00556 \\
\hline $\mathrm{H}_{2}$ & -1.14414 & 0.01059 \\
\hline $\mathrm{H}_{2} \mathrm{O}$ & -76.19685 & 0.02298 \\
\hline
\end{tabular}

\section{B. The Overall Stoichiometry for The Formation of}

\section{L-Cysteine.}

Although Mg.porphin is here taken as the catalyst for the reaction, the overall stoichiometry for the formation of L-cysteine can be represented as follows.

The enthalpy change is negative indicating that there may be energetically favourable routes to the initial formation of the imine. The intermediates by which this stoichiometric reaction may have occurred are as follows:

$$
\begin{gathered}
\mathrm{H}-\mathrm{C} \equiv \mathrm{CH}+\mathrm{NH}_{3}+\mathrm{SH}^{-}+\mathrm{H}^{+}+\mathrm{CO}+\mathrm{H}_{2} \mathrm{O} \rightarrow \mathrm{H}_{2}+\mathrm{C}_{3} \mathrm{H}_{7} \mathrm{NO}_{2} \mathrm{~S} \\
\text { L-cysteine Fig. } 9
\end{gathered}
$$

\section{The Ammoniation of The Mg.Ethynyl.Porphin.}

The positively charged ligand can react with ammonia to form a cis and a trans complex as follows [16-17].

$$
\text { Mg.1,ethynyl.porphin }+\mathrm{NH}_{3} \rightarrow
$$

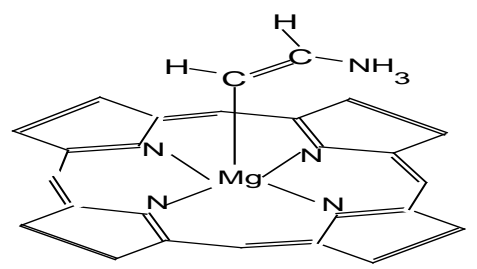

Figure 2. cis Mg.1,2-amino ethenyl.porphin $\Delta \mathrm{H}=0.02209 \mathrm{~h}$ 


$$
\begin{gathered}
\text { Mg.ethynyl.porphin }+\mathrm{NH}_{3} \rightarrow \text { trans Mg.2-aminoethenyl.porphin } \\
\Delta \mathrm{H}=0.04471 \mathrm{~h}
\end{gathered}
$$

The formation of these complexes is the rate determining step in this sequence of reactions. The cis Mg.2-amino ethenyl.porphin complex is the more stable and enables a close proximity of the amine group and the methine carbon atoms of the bound acetylene.

\section{The Formation of Mg.2-Amino Ethylidene.Porphin.}

The cis Mg.2-amino ethenyl.porphin may be transformed by a protropic shift to form Mg.2-amino ethylidene.porphin [16-17].

cis Mg.1,2-amino ethenyl.porphin $\rightarrow$

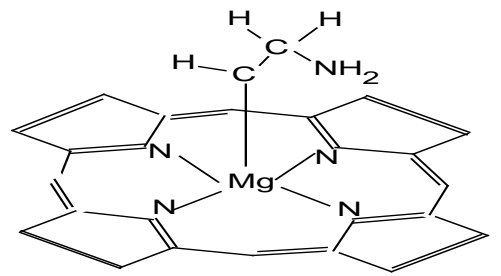

Figure 3. Mg.1,2-amino ethylidene.porphin $\Delta \mathrm{H}=0.04375 \mathrm{~h}$

The activation energy for the amino group to dissociate a proton and to reach the saddle point is given as $0.049 \mathrm{~h}$. [16-17].

\section{E. The Formation of The Mg.1,1H Aziridin-2-Yl.Porphin}

The Mg.2-amino ethylidene.porphin undergoes ring closure to form Mg.1H aziridin-2-yl. porphin.

cis Mg.1,2-amino ethenyl.porphin $\rightarrow$

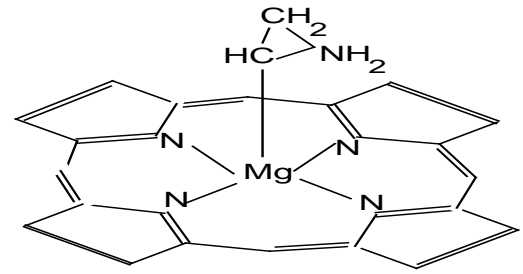

Figure 4. Mg.1,1H aziridin-2-yl. Porphin $\Delta \mathrm{H}=-0.00374 \mathrm{~h}$
The enthalpy change for the ring closure of the cis Mg.2-amino ethenyl.porphin complex is favourable. The complex appears stable with normal bond lengths.

The total energy of the The Mg.1, 2-amino ethylidene.porphin is larger than the energy of the saddle point, so that the activation energy to close the ring is very low, given at the HF level as 0.001 h.whilst the activation energy to open the ring is given as $0.022 \mathrm{~h}$.

\section{F. The Formation of The Mg.1, 1-Amino-2-Mercapto Ethan-1yl.Porphin.}

The Mg.1H aziridin-2-yl. porphin. may react with nucleophilic anions such as hydroxide anion [16-17] leading to the formation of hydroxyethanimine and ultimately the amino acid serine. It may also react with the hydrosulfide anion to form Mg.1,1-amino-2-mercapto ethan-1yl.porphin.

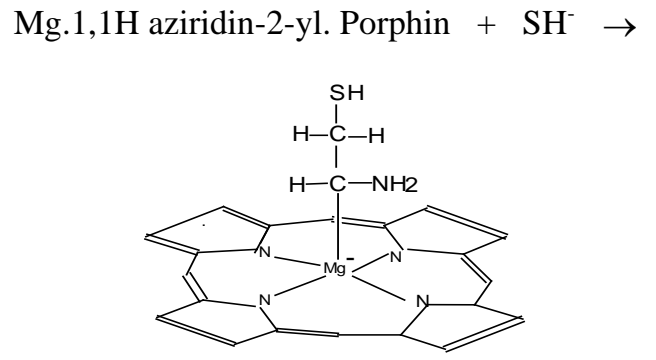

Figure 5. Mg.1, 1-amino-2-mercapto ethan-1yl.porphin$\Delta \mathrm{H}=-0.08900 \mathrm{~h}$

The activation energy to form the S-C bond is estimated at the HF level as $0.110 \mathrm{~h}$ by bringing the hydrogen sulphide anion closer to the $\mathrm{C} 2$ of the aziridinyl ring and $0.069 \mathrm{~h}$ for the reverse dissociation.

\section{G. The Formation of Mg.1, 2-Mercapto Ethanimin-1yl.Porphin.}

The Mg.1, 1-amino-2-mercapto ethan-1yl.porphin may react with hydroxide anion to lead to an imine complex [16-17], or with a proton as shown. 


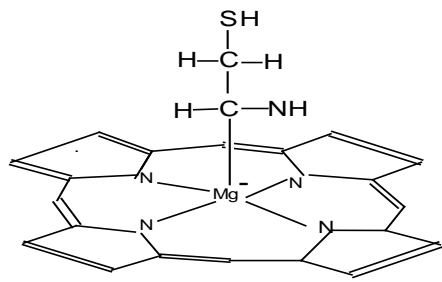

Figure 6. Mg.1, 2-mercapto ethanimin-1yl.porphin

The enthalpy change is, $\Delta \mathrm{H}=-0.56571 \mathrm{~h}$.

The bonding changes from Mg-C to Mg-N during the optimization.

The activation energy was calculated by placing a hydrogen ion at 1.1 A from one of the amino hydrogen atoms, and stretching the $\mathrm{N}-\mathrm{H}$ bond. No activation energy could be discerned from 1.0 to $2.2 \mathrm{~A}$.

\section{H. The Formation of The 2-Mercapto Ethanimine}

The Mg.1, 2-mercapto ethanimin-1yl. porphin is expected to dissociate to a minor extent with a small vapour pressure, but this requires a small activation energy according to the equation.

Mg.1,2-mercapto ethanimin-1yl.porphin $\rightarrow$ Mg.porphin+2-mercapto ethanimine

$$
\Delta \mathrm{H}=0.03867 \mathrm{~h}
$$

\section{The Formation of Mg.1, 2-Mercapto Ethanimin -N-1yl.Porphin.CO}

Imines have been previously shown to react with excited carbon monoxide to form aziridin-2-one complexes [16-17] which should be easily dissociable by heat and hydrolysable.

For the correct formation of the L-isomer the 2-mercapto ethanimine needs to chelate to the magnesium ion on an Mg.porphin which has already obtained the correct orientation of a bound carbon monoxide molecule [10], as shown.

$$
\text { Mg.porphin.CO + 2-mercapto ethanimine } \rightarrow
$$

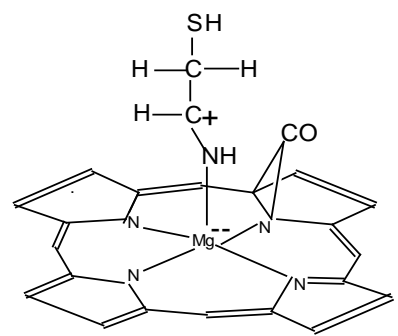

Figure 7. Mg.1, 2-mercapto ethanimin-N-1yl.porphin $\Delta \mathrm{H}=-0.21946 \mathrm{~h}$

The enthalpy change is favourable and the activation energy to form van der Waals complexes is usually not significant if they are spontaneous.

\section{J. The Formation of Mg.1,3-(Mercaptomethanyl)}

\section{Aziridine-2-One-1-Yl.Porphin.}

The Mg.1, 2-mercapto ethanimin-N-1yl.porphin.CO may easily rearrange to form Mg.1, 3-(mercaptomethanyl) aziridine-2-one-1-yl.porphin with an activation energy of $0.159 \mathrm{~h}$ and a ring dissociation energy of $0.153 \mathrm{~h}$.

The enthalpy change is favourable.

$$
\text { Mg.1, 2-mercapto ethanimin-1yl.porphin.CO }
$$

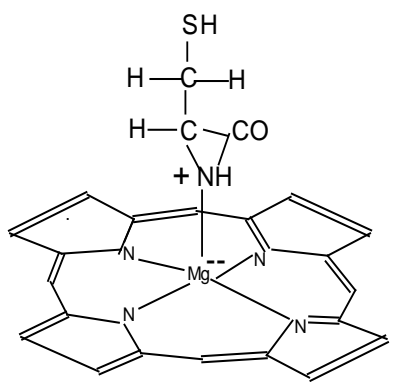

Figure 8. Mg.1,3-(mercaptomethanyl) aziridine-2-one-1-yl.porphin

$$
\Delta \mathrm{H}=-0.0073 \mathrm{~h}
$$

\section{K. The Formation L-cysteine.}

Hydrolysis in the environment of the complex is here depicted as releasing the undissociated acid, Fig.9, from the catalyst. Further formation of the zwitterion may occur and the S-anion.

Mg.1, 3-(mercaptomethanyl)aziridine-2-one-1-yl.Mg.porphin $+\mathrm{H}_{2} \mathrm{O} \rightarrow$ Mg.porphin + L-cysteine (12) 
<smiles>NC(CS)C(=O)O</smiles>

Figure 9. L-cysteine $\Delta \mathrm{H}=-0.03275 \mathrm{~h}$

Such a complex has been inferred as able to polymerise to protein. [16-17]

\section{CONCLUSION}

Although the reaction of ethyne with ammonia may give several products [16-17] it should give the aziridine complex which is shown to be susceptible to nucleophilic attack by hydroxide anion and hydrogen sulphide anion leading to this unique amino acid. This mechanism does not predict the formation of S-methyl cysteine, which is not prevalent, as the methyl group of the Mg.1, S-methyl 2-mercapto ethanimin-1-yl porphin exerts some steric hindrance and the formation of a stable, Mg.1, S-methylthia-2-aza-cyclobutan-3-yl.porphin. The existence of this complex also precludes isomers of the amino acid methioinine.

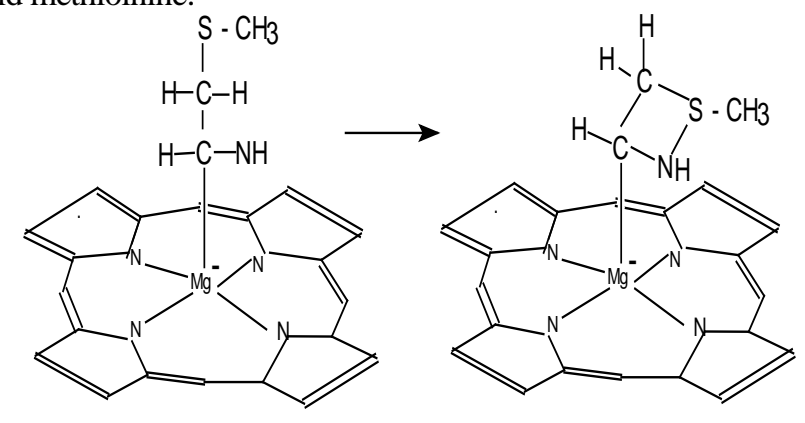

Mg.1, S-methyl 2-thia ethanimin-1-yl.porphin $\rightarrow$ Mg.1,S-methylthia-2-aza-cyclobutan-3-yl.porphin.

$$
\Delta \mathrm{H}=0.14240 \mathrm{~h}
$$

\section{ACKNOWLEDGEMENTS}

Appreciation is expressed for the advice and support given to this project by Professor Curt Wentrup of the University of Queensland.

Appreciation is also expressed to the National Computing Infrastructure facility supported by the Australian Government (grant NCI-MAS g01) and QCIF, and the assistance of Mr.D.Green and H.Hartig.

\section{REFERENCES}

[1] K.Bailey, Proteins, in Rodd,E.H.(ed), Chemistry of Carbon Compounds, Elsevier, Amsterdam, Vol.1B, 1952, pp.1073,1074, 1338.

[2] A.L.Lehninger, Biochemistry,Worth, New York ,1975.

[3] E.E.Conn and P.K.Stumpf, Outlines of Biochemistry, John Wiley Inc.1972, pp.92,95,99,100.

[4] R.N.Ramachandran, Ed., Conformations of Biopolymers, Academic Press,1967, pp.215-233.

[5] N.Aylward, and N.R.Bofinger, Possible origin for porphin derivatives in prebiotic chemistry - a computational study, Orig.Life Evol. Biosph., 35,4 (2005) pp.345-368.

[6] S.L.Miller and L.E.Orgel, The Origins of Life on Earth, Prentice-Hall Inc.,Englewood Cliffs, N.J.,1975.

[7] D.W.Clarke and J.P.Ferris, Photodissociation of cyanoacetylene : application to the atmospheric chemistry on Titan, Icarus, vol.115 (1995) pp.119-125.

[8] K.Seki, M.He, R.Liu and H.Okabe, Photochemistry of cyanoacetylene at 193.3 nm., J.Phys.Chem.,100 (1996) pp.5349-5353.

[9] Z.Guennoun, A.Coupeaud, I.Couturier-Tamburelli, N.Pietri,
S.Coussan, J.P.Aycard, Acetylene/cyanoacetylene complexes:simulation of the Titan's atmosphere chemistry, Chem.Phys.300 (2004) pp.143-151.

[10] N.N.Aylward, and N.R.Bofinger, Carbon monoxide clusters in the formation of $\mathrm{D}$-sugars and L-amino-acids in prebiotic molecular evolution on Earth, in G.Palyi, C.Zucchi, L.Cagliotti, eds., Progress in Biological Chirality, Elsevier,Oxford (GB), 2004, ch2, pp.429.

[11] N.N. Aylward, "The synthesis of terpenes in prebiotic molecular evolution on Earth," in WSEAS New Aspects of Biomedical Electronics and Biomedical Informatics. Eds. C.A.Long, P.Anninos, T.Pham, G.Anastassopoulos, N.E.Mastorakis, 2008, pp.202-207

[12] Gaussian98, Users Reference, Gaussian Inc.,Carnegie Office Park, Bldg.6., Pittsburgh, PA 15106, USA,1998.

[13] W.J.Hehre, L.Random, P.V.R. Schleyer, and J.A.Pople, Ab Initio Molecular Orbital Theory, Wiley, New York, 1986.

[14] J.A.Pople, H.B.Schlegel, R.Krishnan, D.J. DeFrees, J.S. Binkley, M.J. Frisch, R.A.Whiteside, R.J.Hout and W.J.Hehre, Molecular orbital studies of vibrational frequencies, Int.J.Quantum Chem. Symp. vol.S15 (1981) pp.269-278.

[15] D.G.Whitten, I.G.Lopp and P.D.Wildes, Fluorescence of zinc and magnesium etioporphyrin 1 . quenching and wavelength shifts due to complex formation, J.Am.Chem.Soc., 90 (1968) pp.7196-7200.

[16] N. Aylward, A Prebiotic Surface Catalysed Synthesis of Alkyl Imines,in WSEAS Int. Conf. on Biomedical Electronics and Biomedical Informatics. Moscow, Russia, August 20-22 (2009) pp.52-59.

[17] N.Aylward, A prebiotic surface catalysed synthesis of alkyl imine precursors to the amino acids, alanine, serine and threonine, WSEAS Transactions on Biology and Medicine, 6,2 (2009) pp.27-37. 